\title{
On the Cultivation of College Students' Independent Innovation Ability
}

\author{
Xu Yingqian; Hu Junyi*; Fan zengguang; Wang Siyi; Yang hongbin \\ School of Chemical Engineering, University of Science and Technology \\ Liao Ning. Anshan Liaoning 114051, China
}

\begin{abstract}
The development of society requires the improvement of the ability of independent innovation of college students. However, how to achieve the improvement? We need to provide appropriate environments for innovation, which including reforming the teaching mode, providing a complete education; developing the effectiveness and efficiency teacher evaluation criteria; and providing impartial opportunities for students and the driving force of innovation. These appropriate elements will play positive roles in promoting the cultivation of college students. The results of four years of teaching reform on the cultivation of college students' independent innovation ability show that students 'scientific research awareness, hands-on ability and product development ability have been improved, and the awareness of cooperation among student groups has been enhanced so that they have already had strict scientific attitudes and cooperation capabilities.
\end{abstract}

\section{Keywords-Independent; Innovation; Culture; College Student}

\section{INTRODUCTION}

As a group of high level of knowledge, college students shoulder the important task of rejuvenating the nation. Therefore, it is particularly important for the cultivation of college students. The society, school, and family are crucial to the growth of college students. Reform of higher education is our common responsibility, it can not be borne by our country, the government alone. The society, school, and family must recognize its importance and necessity and provide services and supports for the education of university students through the partnership of society, school, and family to meet the needs of all students.

\section{METHODS}

\section{A. Cultivating students' spirit of innovation}

In future jobs, college students not only need to better adapt to the professional needs of the enterprise, but also need to better lead the development of the enterprise. This requires an outstanding spirit of innovation on the part of college students.

\section{1) Reform of the education model}

\section{a) Reality}

In the course of higher education in the past, we used too many fixed and obsolete education models, introducing the opposite direction from the learning process of students, limiting the development of students' thinking and creativity [1].

\section{b) Reform measures}

The new generation of higher education should evolve into a new teaching model with student-centered pluralism, informatization, and ecology. In the future, college classrooms will become a humanized and efficient classroom with intelligence, openness, mixing, and interaction [2]. We should adopt a variety of teaching methods according to teaching content, teaching goals, teaching objects, as well as different choices of teaching time and space and teaching medium. The comprehensive application of a variety of teaching methods can achieve the integrity of teaching, from a single lecture-style teaching to a plurality of teaching methods such as case style, group discussion style, role playing style, project style, and reversing classroom style. The multi-level harmonious interaction between teachers and students can be realized, and the students' creative consciousness and creative potential can be constantly stimulated, so that the comprehensive quality of students can be improved comprehensively, and we need to develop and use a new generation of assessment criteria that meet college and career readiness to better determine whether students have acquired the skills they need to succeed. The new assessment system will better capture high-level skills, provide more accurate student growth metrics, and better feed back classroom teaching to meet academic needs

\section{2) Implementation of a complete college education}

College students must finally enter the society and realize their own values in social groups. Therefore, complete education is particularly important for them. College students need a comprehensive education in order to make suggestions in the construction of enterprises and to become leaders, from science and technology to history, society, foreign languages, art, financial knowledge and other subjects should be covered. Therefore, schools and teachers should implement more complete education and teaching programs based on aptitude, personality development, training programs, and business cooperation programs through improved professional development directions.

The innovation and entrepreneurship mentor committee, corporate experts, and employers jointly study and determine the setting of the university curriculum system so that it meets the needs of the society; In the course content selection, we pay attention to selecting the teaching content of ecological nutrition, avoid the disadvantages of the old knowledge of teaching materials, and choose to reflect the content of the subject frontier knowledge and cross-knowledge. Pay attention to the theory and practice, to train the personnel each 
ecological practice link to carry on the scientific and reasonable design, so that the practice link can really exercise the student's scientific research ability and cultivate the student's innovation consciousness; The theoretical and logical framework of the outstanding disciplines enables students to be trained in systematic science and grow into innovative applied talents that can promote industrial restructuring and economic and social progress.

\section{B. Effectiveness and efficiency of teachers and leaders}

\section{1) Reality}

Effective and efficient teachers and leadership is a favorable guarantee to improve the teaching professional level [3]. In general, the level of academic qualifications of university teachers is obvious to everyone. Generally, they require a doctorate, but the level of practice and the ability to connect with the company are uneven. If the teacher has only stood on the podium for many years and lacks practical ability, it is difficult for such a teacher to master the advanced nature of the subject field and teach innovative students. It is not advisable to build a car behind closed doors, and teachers who are satisfied with the status quo can not meet the needs of society. In addition, a leader with decision-making skills and a broader perspective is also important. The decision-making opinions of the leaders often determine the direction of the school's policy formulation. If the direction is wrong, it will not be able to achieve our stated goals well, or it will take more detour in the process of achieving the goals. As a result, the importance of having excellent teachers and leaders is evident. At present, the evaluation criteria of the school mainly have the following disadvantages:

- Emphasis on scientific research and light teaching;

- The level of assessment of teachers is unclear, one size fits all, and input-output is disproportionate;

- Lack of emphasis on student training and coordination with other partners in scientific research and student practice;

- The evaluation criteria are not objective and require teachers to become versatile.

\section{2) Evaluation criteria}

How, then, to have effective and efficient teachers and leaders? This requires an evaluation system that is studentbased and socially driven, and that identifies effective and efficient teachers and leaders to encourage and reward excellence. An effective evaluation and reward mechanism will play an active role in recruiting, placing, rewarding, retaining and promoting effective teachers, and strengthening teaching standards. These systems will play a positive role in professional development and help teachers and leaders improve student learning. Let everyone who has an academic level and loves education have the opportunity to compete on an equal footing. Perhaps this will break the iron rice bowl of education and increase the sense of crisis among teachers and leaders.
The assessment results mainly include three aspects [4]:

- The use of student growth as an effective and efficient evaluation criterion, including job placement, student growth and subsequent development;

- Ensuring consistency in the definitions of "effective" and "efficient" teachers;

- Provide meaningful feedback to teachers and principals to improve their practice and professional development;

- Develop partnerships with teachers, principals and other education stakeholders to develop effective teachers and leadership.

\section{3) Measures}

Effective and efficient teachers and leaders play a crucial role in raising the level of higher education, and they can not be reduced to mere formality. At present, documents have been made at the national level to encourage teachers and leaders of universities to go abroad, to enterprises, to sister colleges and universities, etc.. And learn from good experience [5]. Only when one sees the head of others can one make up for his own shortcomings; only by seeing the needs of society can the direction of research be clearly defined; only by seeing the frontier of the subject can we learn and apply it. At the same time, more scholars and corporate technicians are encouraged to communicate with each other, learn from each other, and discuss with each other.

Adopt the ecological growth evaluation standard of sustainable development, emphasizing openness and development; Emphasis on people-oriented, personalized and innovative consciousness and other characteristics. Multidimensional, holistic and individualized ecological growth assessments can not only motivate teachers to work and promote their professional development, but also enable students to study more actively and actively, and have the effect of improving, motivating, and authenticating teaching. It is an important means to improve the quality of teaching. Ecological growth evaluation has completely overturned the traditional evaluation criteria and formed a multi-perspective, multi-dimensional and multi-subject evaluation mechanism.

\section{Equal opportunities for students}

Be strictly and fairly responsible for all disciplines and meet the needs of different learners. Schools must be accountable to all aspiring university students and give them equal opportunities, including funding, including support, including the provision of appropriate guidance and guidance. Whether or not he is a dominant discipline, or a popular major, it can not be ignored because the discipline is not the mainstream of society for the time being or there is currently no outstanding achievement in the field. For non-mainstream disciplines, there is a need to continue to support and strengthen attitudes and to ensure that standards are in place to help them establish University and career readiness. The most important thing is to help all students realize the challenges and opportunities of their subjects and encourage them to challenge themselves according to the needs of society. 


\section{Innovation promotion}

\section{1) Invest in innovation funds}

Financial support is a necessary condition for carrying out scientific research activities. The state, society, and schools will support the scientific research and innovation activities of college students and provide certain funds to support and guarantee them. Students are encouraged to convert scientific research results into productive forces and to solve practical problems in production through innovative thinking. Encourage and reward students 'innovative awareness and activities, and create more, larger, and more flexible special funds to encourage and support students' success.

\section{2) Developing a criteria for the use of funds and incentives}

In terms of reward standards, based on consistent standards, strict and fair evaluation teams and individual students, rewarding the progress and success of task groups and individuals, in order to encourage backward students, it also needs to be flexible to determine appropriate improvement and support strategies.

\section{3) Rewarding progress and success}

In the process of implementation, schools will design innovative funding schemes that reward non-dominant disciplines. Incentives may include financial incentives for staff and students and participation in "community of practice" scientific awards, sharing research experience, and assisting underperforming disciplines and graduate students. Incentives also allow flexibility, where appropriate, to reward superior disciplines and high-demand disciplines. Incentives will also provide flexibility in the implementation of interventions and appropriate policies for major, continuing disciplines. On the other hand, for the challenge strategy, interventions will be needed to support the gaps in the weak and small disciplines. The specific measures are as follows:

- Transformation mode: introduce team leaders, introduce new ideas, and change ideas.

- Turnover mode: replace the main body and reoccupy no more than 50 team members.

- Reboot mode: convert or close the reorganization task force to establish an effective management organization or educational management organization.

- Dissolution of the task group model: Dissolution of the task group and redistribution of the members of the group.

\section{4) Working Capital Fund}

The remaining funds will be competitively awarded to other disciplines for scientific research and practical activities.

\section{CONCLUSION}

Independent education is an educational concept that is coordinated and balanced within and outside the country. It guides students to study independently, independently develop course activities and social practices, and cultivate students ' independent abilities [6]. After several years of teaching reform practice, it has also achieved fruitful results. It has cultivated students 'scientific research consciousness, improved students' hands-on practice ability and product development ability, cultivated students 'good team cooperation consciousness, and made full use of the resources of teachers, teaching, and scientific research in schools to teach students in accordance with their talents. Students cooperate in the experiment, learn from each other, and cultivate a rigorous scientific attitude and cooperation ability. Taking the School of Chemical Engineering of Liaoning University of Science and Technology as an example, students 'satisfaction and satisfaction rate for practical teaching is more than $99 \%$. Students learn through systematic professional knowledge, and the quality of all aspects has been significantly improved. Since 2014, the employment rate of students majoring in chemical engineering has reached $100 \%$, which has been well received by employers. This reform coincides with the country's recent educational reform ideas, emphasizing independent education to train students to be "the best of themselves." Let each individual grow into a self-owner who thinks and acts through his own efforts, cultivates his own altruism, and advances to good.

\section{ACKNOWLEDGMENT}

Funds: China Institute of Degree and Postgraduate Education Issues (topic number: 2015Y0502); University of Science and Technology Liaoning's Experimental Teaching Reform Project 2017; University of Science and Technology Liaoning 2018 Innovation and Entrepreneurship Education Teaching Research Special Topics The Main Responsibility and Open Growth Platform of Undergraduate Teaching in Innovation and Entrepreneurship Education GJ18YB10; University of Science and Technology Liaoning Graduate Education Reform and Technology Innovation and Entrepreneurship Project(Project No : 2017YJSCX01)

Introduction: Ying-QIan Xu (1974- ), female, associate professor, doctor, master tutor, research direction: biology and food engineering. Email: hjy741110@163.com.

Correspondent: Jun-Yi Hu (1974- ), male, professor, doctor, master tutor, research direction: Chemical Engineering. Email: 276475065@qq.com.

\section{REFERENCES}

[1] Fan Yang. An Analysis of Classroom Teaching Patterns in Colleges and Universities [J]. Journal of Xuzhou Normal University (Education Science Edition), 2012(3): 43-45.

[2] Shi-ming Li, Jun Jiang. Study on the Strategy of Solving the Homogenization of Classroom Teaching Patterns in Colleges and Universities [J]. Journal of Heilongjiang Institute of Education, 2012(1): 51-53.

[3] Zhangyan, Mazhaoyun, Zhang Yong. Effectiveness of International Training of Applied Undergraduate Teachers [J]. Jiangsu Gaojiao, 2018(1): 61-64.

[4] The Reauthorization of the Elementary and Secondary Education Act. A Blueprint for Reform. U.S. Department of Education.

[5] Huangweiwei, Ban Rongding, Zhangbo. An Analysis of the Impact of the State's Policy on Encouraging Innovation and Entrepreneurship among Teachers in Colleges and Universities. Higher Education Forum, 2017. 8: 123-126.

[6] http://edu.people.com.cn/GB/n1/2018/0517/c367001-29996700.html. 